\title{
BRIEF REVIEW ON INTERNATIONAL TRADE
}

\section{PRAFULLA K SWAIN \& BIBHUTI B PRADHAN}

Department of Management, Siksha 'O'Anusandhan (Deemed to be University), Bhubaneswar, Odisha

\begin{abstract}
In a country economy and the global economy, foreign trade is a crucial factor. In general, trade barriers in foreign policy are toughest to enforce, but they play a major role in the business sector and their rival's International trade has significantly contributed to the global economic system. The International Trade Policy has influenced many countries in the world to pursue international economic policies encouraging greater trade and investment. Economic policies were introduced in the Emerging Market Economies (EME).BRIC's acronym means that the leaders of these emerging-market economies are Brazil, Russia, India and China. The growth and prosperity of these countries was underpinned by international trade. This report offers facts and figures on foreign trade activities and how their rise and development in emerging market economies are promoted. Several foreign trade hypotheses have been used to justify these trade practices. This includes Heckscher-Ohlin, Rechardian and Foreign trade gravity models. The researchers criticize emerging-market economies for these great positions played by foreign trade and make practical recommendations to them. Most markets today are dominated by big corporations and sometimes controlled. Others are the only (monopoly) supplier or in general one of the few (oligopoly) suppliers not only on a regional level but also on a global level. In Western Europe, the development of capitalism and its beginnings during the 19th century is generally attributed to the expansion of free trade and free markets.

KEYWORDS: Competition Market, Economic Growth, Emerging Market Economies, International Trade, Investment
\end{abstract}

Received: Jun 06, 2020; Accepted: Jun 26, 2020; Published: Aug 26, 2020; Paper Id.: IJMPERDJUN2020889

\section{INTRODUCTION}

The international trade policy has made a major contribution to the growth and prosperity of many countries worldwide. Research has shown that foreign trade in the world today has been more competitive than ever in modern history. For several countries worldwide, this policy has promoted foreign economic policies that foster further trade and investment. Countries engaged in international trade typically function under one or the other arrangement, such as a multilateral, bilateral and regional agreement. The 1994 General Trade and Tariff Agreement (GATT), however, were replaced by the World Trade Organization (WTO), which governs all registered countries of foreign trade members. This group also contains the emerging markets economies that are registered members. Brazil, Russia, India and China are the leading economies on the developing market known as BRICs.[1] These countries were assisted in their growth and development sectors by international trade activities. It is one of the most contentious issues for the development today that globalization can be a big positive factor in reducing global poverty. The labor market is the main medium that can affect globalization. Increased integration with the global economy is likely to reduce poverty by generating new employment in export industries. More transparency, however, also raises import competition for previously secured industries. It could result in job cuts in some industries, with employees being reduced to poverty. This is essentially an empirical question that globalization generates or kills jobs, and who is the winner and loser of work. Whilst it is important to understand 
the relationship between globalization and poverty, few empirical studies have been carried out on the effect of foreign trade on jobs in developing countries1. Much of the initial work was done in this field in a multiple-country study funded in the early 1981s by the National Bureau of Economic Research. Jenkins and Sen. recently analyzed the impact on employment in 4 developing countries-Bangladesh, Kenya, South Africa, and Vietnam of trade flows and foreign investment. This study demonstrated the significant increase in the number of non-qualified workers, particularly for women, in Bangladesh and Vietnam in the integration with the world economy.

However, development of jobs in Kenya and South Africa as a result of increased transparency has been low and favors more qualified citizens. This work indicates that the pro-poor effects of globalization could have a continental divide, whereas Asian economies benefit more from increased global integration than African economies. However, it is not clear whether such a inference is reliable and why this continental division exists? What can explain? A significant point here is Wood who predicts that the long-term course of Africa's growth will be more similar to land-rich America than land-scarce Asia. Wood claims that the high land-working ratio in Africa to the Asian ratio means that in labor intensive manufacturing Africa has a comparative advantage rather than Asia. Thus the variations in the Factor Endowments between Africa and Asia are explaining why the export structure of Africa is more focused than unskilled labor intensive manufacturing exports towards natural resource-based commodities. One corollary to this statement is that globalization, since manufacturing which is labor intensive seems to be the main industry in developing countries and that has benefited the most from the rise in world trade in recent decades, would unlikely have the same positive effect on the production of jobs in African countries as in Asia.[2] Wood's statement provides the findings obtained by Jenkins and Sen. with a plausible interpretation.

However, some questions remain unanswered. Second, how robust is an obvious continuous divide to be discovered. Is this significant driver of the job gaps between Bangladesh and Vietnam, on the other hand, and Kenya and South Africa, on the other, in other Asian countries with an abundance of non-expert labor relative to land? Second, how critical is the policy regime in mediating the relationship between manufacturing factor endowments and favors? Could it be argued that preferred policies for export-oriented foreign direct investments might have been greater in Bangladesh and Vietnam than in other Neighboring countries in the region to explain the substantial rises in labor-intensive exports in both countries? Thirdly, is it necessary to decide the extent of the impact on the labor market of globalization how international integration is increased? There is partial evidence of the limited labor losses incurred by import penetration of Vietnam's incremental trade reforms as opposed to South Africa, which contributed to a more rapid radical liberalization of trade. Finally, does foreign trade generally have a beneficial effect on jobs even in non-qualified labor-intensive sectors or industries? As companies struggle to compete against imports or on global markets, there may be job losses due to technological change triggered by trade. Evidence from South Africa and Vietnam suggests that sectors subject to penetration by imports were most likely to save labor. This topic means that only a detailed comparative study involving countries which differ from the previous four countries in terms of factor endowments and political structures that be carried out on the effect of globalization on employment results in developed countries.[3] The current paper builds on Jenkins and Sen.'s work to enable to understand how globalization impacts on the labor markets of the developed world in a dynamic and contradictory manner. For the period 1976-1998, for which industry data are available, we will conduct a case studies in India. The Indian experience on manufacturing globalization is important to remember in view of the high poverty levels in the country and the limited possibility of agricultural growth driving poverty reduction in many parts of the world. In the case of Bangladesh, it has similar factor endowments-, abundant supplies of unskilled work - but, in 
particular, a relatively bad environment for foreign direct investment and regulations of the labor market which restricting small- to medium- enterprises 'flexibility Indian offers an interesting contrast to Bangladesh. However, through a series of decades of export-related industrialization, India has well developed technological capacity and an extensive pool of scientific and technical workers that can enable Indian firms to penetrate world markets through goods which are not inherently skilled in labor. They can either withstand import competition in capital-conscious industries. This means that the effects of globalization will vary considerably from those seen in Bangladesh on the labor market in India. The key question to answer in the paper is whether or not commercial integration in the Indian manufacturing sector has produced or damaged jobs.[1]

\section{THEORETIC SYSTEM OF INTERNATIONAL BUSINESS}

Various scholars offer various theories of international commerce. Among these theories are; The model Recardian, krugman and obstfeld notes that, on the principle of comparative profit, this model is developed. Within this model, trading countries are skilled in the production of goods that have a competitive advantage. For example, if country A and B involve producing Y clothes and X cars, and country A produces more clothing per day for less and less cars at a high cost per day, and country B produces less clothing at a high cost per day, and a higher number of cars at less cost per day. That is the case in the case of countries A and B. "A" would manufacture amounts of clothes in contrast to "B" because of the benefit they have on manufacturing costs over each other. This model, Heckscher-Ohlin, emphasizes development donor factors as the basis for international trade. According to this theory, countries specialize in and export goods that make greater use of domestic development factors than are the factors that are not present in the country of origin. It is mainly focused on the abundant output factor available. A nation should only export what it has and import what it doesn't have in abundance.[4]

The principle of gravity-this principle provides scientific explanations for world trade. The model shows that the key factors deciding the pattern of foreign exchange are economic sizes and the gap between nations. The model is similar to the Newtonian gravity law, which also takes account of the distance of two bodies from one another. The model notes that foreign trade is determined by the size of the two countries 'GDPs and the difference between them by the amount of trade between them, without explicitly stating that trade is proportional to and inversely proportional to the GDPs' value. In other words, the value of trade is proportionate to the GDP product of both countries that decreases with the distance between the two countries. Not all theories of trade suggest that increased trade would inevitably result in more laborintensive production composition in developed countries. It relates primarily to cases of inter-industry trade and is much less relevant where inter-industry trade is concerned.[2]

Nevertheless, as shown in the latter case by Fenestrate and Hanson, trade will increase the demand for the scarce factor in the developed countries, contrary to the orthodox Heckscher-Ohlin forecast. In any case, intra-industry trade may represent economies of scale and differentiation of products rather than factor endowments. Also, regardless of the factors leading to these shifts, these reviews refer to the impact of shifts in weights of various produce sectors on jobs as the compositional effect. The last way foreign trade can have an impact on manufacturing employment is by changing the industry, which is responsible for the quantity and type of work needed to manufacture a certain product. In the conventional theory of trade, the adjustment is due to a variance in relative price factor induced by changes in relative demand with the opening up of the economy. This in effect contributes to output factor substitution. The impact on employment of industry rates can also be achieved through induced productivity effects as firms release work due to 
greater export orientations or increased import penetrations in response to external competitive pressures. A decline in $\mathrm{x}$ inefficiency could result in a trade-induced productivity impact because the trade reform leading to greater international competitiveness leads to a decrease in 'weak' labor input. It may also be caused by technological changes triggered by trade (e.g. by an increase in capital imports). The process effect of foreign trade applies to all of these impacts from trade on employment within manufacturing industries.[5]

\section{CONCEPTS OF EMERGING MARKETECONOMIES ANDINTERNATIONAL TRADE}

Emerging market economies: There are so many definitions provided by different scientists of emerging market economies. Economy Watch has described emerging market economies as low-capital-income economies. The EME countries make up about $82 \%$ of the world's population and around $22 \%$ of the world's economies. AntioleAgtmeal was invented in 1981 and worked at the World Bank's international finance agency. The author added that emerging market economies have a required definition of trade liberalization and are making their markets accessible or exposed at a global level. This opens the way to other international goods that now compete with local products in the domestic market. It enhances and increases their productivity and also helps to generate export value products in the model of domestic goods and services.[6]

Williams described an emerging market economy as an economy that followed rapid economic growth, expansion of foreign investment and growing political power around the world. Clear economic statistics, such as the increasing GDP, GDP per capital, trade volumes and foreign reserves, is proof of rapid economic development. Quick growth typically means greater income for foreign investors, which boosts international investment in a country that, in effect, promotes economic development. In 2002, Jim O'Neill, who was inventing BRIC, said, was suggesting that this idea of emerging market economies (EME), will lead world economic growth over the next 52 years, over relation to Brazil, Russia, India and China. From this time on, many academics, economists and journalists wrote a lot about the BRIC theory, and the acronym became popular.[7]

International trade: International trade involves the movement of products and services from one country to another, including capital goods. This interpretation was in line with Economics Principles, which described it as international trade. This trade constitutes an significant proportion of the gross domestic product (GDP) of most countries. International trade has a long history and its cultural, social and political significance has grown over the last few centuries. Thus, nations are restricted to goods and services manufactured within their own borders without foreign trade.[6] The Economics Theory states, however, that the distinction between domestic trade and foreign trading is that such trade is more expensive than domestic trade. That is because foreign trade needs certain charges or expenses such as tariffs and because it often includes extra costs due to regional differences, such as language, law or culture. Development factors such as capital and labor usually travel within a country more freely than across countries. These determinants therefore give business people and organizations a strong polarization of the two principles. [6]

\section{TRADE POLICY IN INDIA}

After independence, the import and export regime adopted by Indian politicians has aimed at absolute, direct regulation of foreign exchange use and overwhelming reliance on quotas rather than tariffs. The allotted import licenses represented two main criteria: 1) the 'essentiality' principle; and 2) the non-availability principle of indigenous peoples. Imports should therefore only be permitted in terms of both size and composition if, as inputs or production apparatus, the business in 
question attests to the Government that they are 'necessary.' Around the same time, from an indigenous availability point of view, the government had to clear the imports: if it could be proven that the imports were required for domestic output, the imports were not permitted (in any cost or qualitative considerations). Nearly all imports were allowed on a contractual basis or were "channeled" by government trade monopolies. The only exceptions were the products listed in the category OGL[8].In the case of capital goods, the category and the OGL class was limited. Although restricted capital goods need import licenses, OGL products may be imported under many conditions without a license. In addition to OGL categories intermediate goods have been categorized into restricted, limited and approved categories. As indicated by these titles, the first three lists were limited to import licenses. The 'real customer' condition was still used to regulate OGL imports of intermediate goods; however the importation of consumer products was prohibited. However, the import restrictions were slowly but sustainably decreased from the exportation import policy of 1978-79.[9] Several products of capital which could not be imported without an import license were constantly moved to the group of OGL. In April 1989, the OGL list had raised the number of capital goods from 79 in 1976 to 1170. Several reforms have been made to modernize domestic industries. In addition, during the 1980s, less stringency was introduced with the import licensing of capital goods under the limited list. Consequently, in the capital goods sector the import penetration ratio has risen from $12 \%$ in $1978-79$ to $18 \%$ in $1986-87$.

The continuous change from restricted and permissible categories to the OGL category also occurred for intermediate products. In practice, however, only if a capital or an intermediary good was not created at home was included in the OGL list. Thus, during this time import liberalization may have resulted in some competitive rates for wellestablished producers of intermediate goods in India (although in some cases, imperfect substitutes of domestically produced products were the products which were permitted to be imported). The continuous change from restricted and permissible categories to the OGL category also occurred for intermediate products. In practice, however, only if a capital or an intermediary good was not created at home was included in the OGL list. Thus, during this time import liberalization may have resulted in some competitive rates for well-established producers of intermediate goods in India (although in some cases, imperfect substitutes of domestically produced products were the products which were permitted to be imported). The new administration also stressed export promotion at the start of the mid-1980s. The number and importance of export opportunities has been increased and their administration has been streamlined. REP permits, traceable import exemptions for exporters on the basis of particular goods, became increasingly generous. Eventually, the duty-free regime for imported inputs was expanded for imported inputs to include both direct and indirect exporters 'imported inputs.[10]

In 1992, a significant liberalization of the trade system in respect of capital goods was initiated as part of the comprehensive program for economic reform that year. The import license for most machinery and equipment and intermediate goods was effectively abolished. Tariff rates have decreased significantly, with the high rate decreased from 300 to $150 \%$, and the overall tax on capital goods decreased to $82 \%$. Weighted customs tariff rates for imports have decreased from an average of $96 \%$ in $1990-91$ to $29 \%$ in 1995-96. Nevertheless, the trade policy on consumer goods has changed nothing and has stayed on the negative list. Radical trade reforms in 1991 coincided with a equally significant package of industrial policy reforms. A program of industrial private sector licensing had been implemented prior to 1991, which regulated virtually all aspects of company behavior, not only entry in industry and capacity expansion, but also technologies and product mixes as well as the position of capacities and import material. In 1991, attempts to liberalize regulations were previously divided in a systematic wave of domestic deregulation. Save for a handful of environmentally 
sensitive sectors, industrial permits were scrapped entirely. Furthermore, there is the elimination of limits on combining and expanding large business groups and the opening up of the previously reserved public sector sectors to the private sector.[11]

The importance of foreign trade was expressed in the Indian economy. Exports plus imports are also used as an indicator of openness based on results as a ratio of GDP (Fig.1). For products and services and products only, calculations are made. As is well established, India has in recent years been a major exporter of IT services. This represents an improvement in the export ratio plus imports of products and services in relation to GDP in contrast with the export ratio plus imports of only commodities in relation to the GDP. Yet since the late 1980s, the export plus importation ratios of products into GDP have risen steadily and in 2005 the figure has reached approximately $25 \%$. Clearly, Indian economy has greatly strengthened its incorporation into the global economy after the trade reforms of the 1980s and early 1990s. [12]

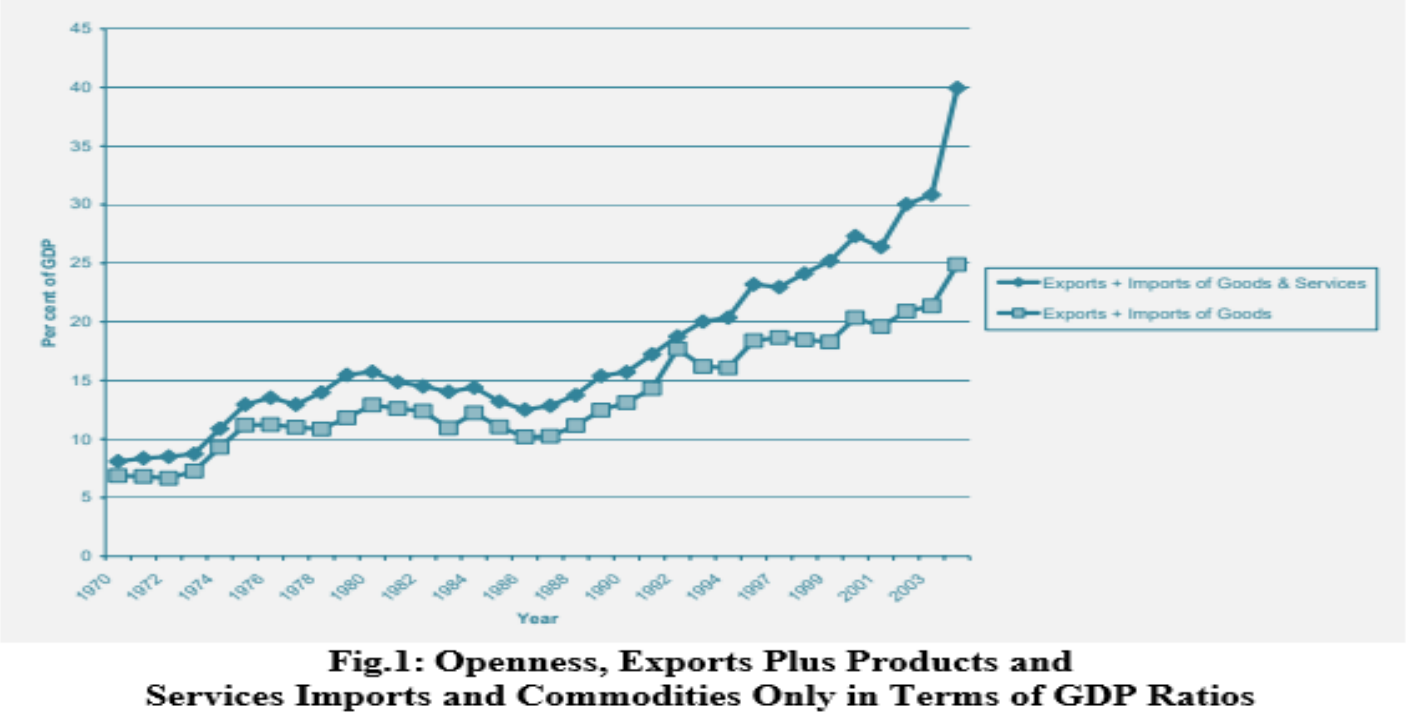

\section{CONCLUSIONS}

In summary, the study examined the important contribution made by foreign trade to the growth and development of emerging market economies. The thesis has been carried out in academic research and offers a better view of the critical evaluation of positions of foreign trade in the developing economies. This is because international economic policies have been implemented that encourage greater foreign trade and investment. The system would be a forgotten history if foreign trade had not been a part of the growth of countries. Also this question of strategic evaluation of positions foreign exchange has not emerged in emerging market economies. The functions found in this study include foreign trade for emerging-market economies: providing additional resources for emerging-market economies support by member-country multilateral, bilateral and regional trade treaties, economic growth and overall revenue increase in member states, and the promotion of natural endowment. Nevertheless, researchers have criticized the fact that FDI's availability has a negative effect on the emerging markets. The problem of dumping is also triggered by foreign trade between some member countries, such as China and North America. 


\section{REFERENCES}

1. J. J. Dethier and A. Effenberger, “Agriculture and development: A brief review of the literature,” Econ. Syst., 2012.

2. S. Sen, “International Trade Theory and Policy: A Review of the Literature," SSRN Electron. J., 2012.

3. T. Chaney, "The network structure of international trade," Am. Econ. Rev., 2014.

4. G. King, R. O. Keohane, and S. Verba, Designing Social Inquiry. 2019.

5. P. Antràs and S. R. Yeaple, "Multinational Firms and the Structure of International Trade," in Handbook of International Economics, 2014.

6. K. Manova, “Credit constraints, heterogeneous firms, and international trade,” Rev. Econ. Stud., 2013.

7. I. Colomina and P. Molina, "Unmanned aerial systems for photogrammetry and remote sensing: A review," ISPRS Journal of Photogrammetry and Remote Sensing. 2014.

8. T. G. Schmitz and A. Schmitz, "International Trade," in Encyclopedia of Agriculture and Food Systems, 2014.

9. P. C. Mishra, S. Mukherjee, S. K. Nayak, and A. Panda, “A brief review on viscosity of nanofluids, ”Int. Nano Lett., 2014.

10. Z. S. Iro, C. Subramani, and S. S. Dash, “A brief review on electrode materials for supercapacitor," International Journal of Electrochemical Science. 2016.

11. S. A. Haas and D. R. Schaefer, “Policy Brief,” J. Health Soc. Behav., 2014.

12. M. Allahyari et al., "Text Summarization Techniques: A Brief Survey,” Int. J. Adv. Comput. Sci. Appl., 2017. 

